\title{
Mutations in Coagulation Factor VIII Are Associated with More Favorable Outcome in Patients with Cutaneous Melanoma
}

\author{
Zheng Ping ${ }^{1}$ Abha Soni ${ }^{1}$ Lance A. Williams III ${ }^{1}$ Huy P. Pham ${ }^{1}$ Malay K. Basu ${ }^{2} \quad$ X. Long Zheng ${ }^{1,2}$ \\ ${ }^{1}$ Division of Laboratory Medicine, The University of Alabama at \\ Birmingham, Alabama, United States \\ 2 Division of Informatics, Department of Pathology, The University of \\ Alabama at Birmingham, Alabama, United States \\ Address for correspondence $X$. Long Zheng, MD, PhD, Division of \\ Laboratory Medicine, Department of Pathology, The University of \\ Alabama at Birmingham, WP P230K, 619 19th Street South, \\ Birmingham, AL 35249, United States (e-mail: xzheng@uabmc.edu).
}

TH Open 2017;1:e113-e121.

\begin{abstract}
Keywords

- coagulation factors

- tumor metastasis

- factor VIII

- von Willebrand factor

- ADAMS/ADAMTS13

Coagulation factor VIII (FVIII), von Willebrand factor (VWF), and ADAMTS13 (a disintegrin and metalloprotease with thrombospondin type 1 repeats 13) play an important role in the regulation of normal hemostasis. However, little is known about their roles in patients with malignancy, particularly with cutaneous melanoma. Whole genome sequencing data are available for 25,719 cases in 126 cancer genomic studies for analysis. All sequencing data and corresponding pathology findings were obtained from The Cancer Genome Atlas. The cBioPortal bioinformatics tools were used for the data analysis. Our results demonstrated that mutations in genes encoding FVIII, VWF, and ADAMTS13 were reported in 92 of 126 cancer genomic studies, and high mutation rates in these three genes were observed in patients with cutaneous melanoma from three independent studies. Moreover, high mutation rates in FVIII, VWF, and ADAMTS13 were also found in patients with diffuse large B cell lymphoma (22.9\%), lung small cell carcinoma (20.7\%), and colon adenocarcinoma (19.4\%). Among 366 melanoma cases from TCGA provisional, the somatic mutation rates of FVIII, VWF, and ADAMTS13 in tumor cells were 15,14 , and $5 \%$, respectively. There was a strong tendency for coexisting mutations of FVIII, VWF, and ADAMTS13. Kaplan-Meier survival analysis demonstrated that melanoma patients with FVIII mutations had a more favorable overall survival rate than those without $F$ III mutations $(p=0.02)$. These findings suggest, for the first time, that the FVIII mutation burden may have a prognostic value for patients with cutaneous melanoma. Further studies are warranted to delineate the molecular mechanisms underlying the favorable prognosis associated with $F V I I I$ mutations.
\end{abstract}

\section{Introduction}

The link between coagulation and malignancy has been recognized for over a century. ${ }^{1,2}$ Thrombosis is a common cause of death in cancer patients. Pulmonary embolism (PE) was more commonly detected in cancer patients at autopsy than in those without malignancy. ${ }^{3}$ PE may also be the presenting signs of an underlying occult malignancy. ${ }^{4}$ In addition, it is accepted that coagulation activation and platelet activation in the tumor microenvironment may

received

August 9, 2017

accepted after revision

August 31, 2017
DOI https://doi.org/

10.1055/s-0037-1607337. ISSN 2512-9465. have a biological significance affecting tumor growth and dissemination (or metastasis).

Cutaneous melanoma is a common skin cancer with an incidence rate of 14.1 per 100,000 inhabitants per year, ${ }^{5}$ arising from the pigment-containing cells known as melanocytes. Ultraviolet radiation from sunlight or tanning devices can induce malignant transformation of these cells by inducing DNA damage, especially in fair-skinned individuals. In addition to the environmental factors, genetics and/or immune status (c) 2017 Georg Thieme Verlag KG Stuttgart . New York
License terms

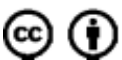


may also play a role in the malignant transformation. When mutations persist in proto-oncogenes, an uncontrolled rate of mitosis could lead to cell transformation and tumor formation. The levels of activating transcription factors in the nucleus of melanoma-inducing cells are associated with increased metastatic activity. ${ }^{6}$ If early diagnosis is made, surgical excision is curative. However, once it metastasizes, the prognosis can be dismal, because metastatic melanoma does not response to chemotherapy, immunologic therapy, or radiotherapy. ${ }^{7}$

Previous studies have demonstrated that VWF, FVIII, platelets, and other procoagulants, such as tissue factor, factor $\mathrm{X}$, and thrombin, may not only result in the development of deep vein thromboembolism, but may also be associated with metastasis of malignant melanoma. ${ }^{8,9}$ Plasma levels of VWF antigen are elevated in patients with metastatic melanoma, primarily resulting from activation of endothelium. ${ }^{10}$ Depending on the experimental model, $v w f$-deficient mice are reported to exhibit either significantly increased or reduced metastatic potential. ${ }^{11,12}$ Analysis of blood samples of metastatic melanoma patients demonstrated that increased plasma levels of procoagulant proteins such as $\mathrm{VWF}^{13}$ and vascular endothelial growth factor $A$ (VEGF-A ${ }^{13}$ and decreased expression or ADAMTS13 (a disintegrin and metalloprotease with thrombospondin type 1 repeats 13) activity create an environment that promotes tumor-associated thrombosis. ${ }^{13}$

FVIII is an important procoagulant protein that binds to VWF with high affinity. In the coagulation cascade, thrombin activates FVIII to form FVIIIa, which dissociates from VWF and acts as a cofactor for factor IXa to activate factor X, which then activates prothrombin to form more thrombin. Thrombin cleaves fibrinogen to fibrin, which stabilizes platelets and clots. ${ }^{14}$ Previous studies have demonstrated the association between baseline plasma FVIII activity in cancer patients, specifically in those with breast, colorectal, and cutaneous malignancies. ${ }^{15,16}$ However, the association between the genetic alterations in the gene encoding FVIII, WWF, and ADAMTS13 and long-term outcomes in patients with cutaneous melanoma has not been investigated in a large cohort of datasets.

This article takes advantage of the recent whole exome sequence (WES) datasets, mRNA expression (RNA-seq) data, and bioinformatics tools to determine the prognostic value of somatic mutations in FVIII, VWF, and ADAMTS13 in cutaneous melanoma. Our results demonstrate that somatic mutations in FVIII, but not in VWF and ADAMTS13, are associated with a more favorable survival outcome. Further investigation of the molecular mechanism underlying how FVIII mutations are associated with a better outcome will help understand the pathogenesis of cutaneous melanoma, which may lead to the development of a novel therapeutic for such malignancy.

\section{Materials and Methods}

Data Mining with cBioPortal and TCGA Browser v0.9 Using cBioPortal, cross cancer studies were first performed to identify cancer studies with the highest mutation rates within FVIII, VWF, and ADAMTS13 genes. Since the top-5 identified studies were all melanoma-related projects from different institutions, we focused on analyzing these three genes in melanoma datasets. All searches were performed according to cBioPortal's online instructions (http://www.cbioportal.org/ index.do). The survival analysis related to mRNA expression of $V W F$ was performed on the TCGA Browser 0.9 from the University Hospital Zurich (http://tcgabrowser.ethz.ch:3839/ TEST/). The mRNA expression of $V W F$ was ranked from high to low, and the top one-third cases were defined as "high VWF," while the bottom one-third of cases were defined as "low VWF."

\section{Melanoma Datasets for Analyses and Validation}

As of June 4, 2017, the cBioPortal includes five melanoma datasets. The provisional "TCGA skin cutaneous melanoma" is the largest one with a total of 479 samples. Of these, 113 cases without mutation data were excluded from our study and the remaining 366 cases were used for further analyses. The corresponding clinical and pathological information associated with the patients in this dataset was downloaded from both the NCl's Genomic Data Commons (https://gdc-portal.nci.nih.gov/) and the cBioPortal. The data from the two sources were compared to ensure that the most up-to-date clinical and pathological information was used for this analysis. The mutation pattern in FVIII, VWF, and ADAMTS13 genes was found to be similar in the second cohort of 121 Broad patients ${ }^{17}$ and the third cohort of 91 Yale melanoma patients. ${ }^{18}$

\section{Selection of the Melanoma Diagnostic Features}

The pathologic criteria used to determine any correlation with the mutations were based on the current WHO classification of human cutaneous melanoma and the AJCC cancer staging manual, 7th edition, including tumor depth (Clark's level and Breslow's thickness), tumor size, tumor site, lymph node, and metastasis status.

\section{Statistical Analysis}

Clinical and pathological predictors in this study are listed in - Table 1. The primary outcome is the mortality rate. Fisher's exact test was used to compare the categorical variables between the group with FVIII mutations and those without FVIII mutations. The Student $t$-test was used to compare the continuous variables between the subgroups. Univariate analysis was performed using the log-rank test to correlate each clinical and pathological predictor with survival outcome. All tests were performed using the XLSTAT version 2014 (Addinsoft XLSTAT, France). All p-values were nonpaired and two sided. $p$-Values less than 0.05 and 0.01 are considered to be statistically significant and highly significant, respectively.

\section{Results}

\section{Mutations in FVIII, VWF, and ADAMTS13 in Various Malignant Neoplasms}

The cBioPortal database has collected a large group of cancer genomic sequencing data. As of June 4, 2017, there were 25,719 samples from 126 cancer studies. In all cancer studies, the mutations in FVIII, VWF, and ADAMTS13 were reported in 93 cancer studies. The top-5 studies were all melanoma studies from different institutions with the mutation rates ranging from 24 to $50 \%{ }^{18,19}$ High mutation rates in FVIII, 
FVIII Mutations and Melanoma Outcome Ping et al. e115

Table 1 Patient characteristics of categorical variables in FVIII-mutated and FVIII nonmutated groups

\begin{tabular}{|c|c|c|c|c|c|c|}
\hline \multirow[t]{2}{*}{ Variable } & \multirow[t]{2}{*}{ Categories } & \multicolumn{2}{|c|}{ FVIII nonmutated $(n=312)$} & \multicolumn{2}{|c|}{ FVIII mutated $(n=54)$} & \multirow[t]{2}{*}{$p$-Value } \\
\hline & & Number of cases & $\%$ & Number of cases & $\%$ & \\
\hline \multirow[t]{2}{*}{ Gender } & Female & 118 & 37.8 & 22 & 40.7 & 0.835 \\
\hline & Male & 194 & 62.2 & 32 & 59.3 & 0.835 \\
\hline \multirow[t]{4}{*}{ Race } & Asian & 9 & 2.9 & 1 & 1.9 & 0.641 \\
\hline & Black & 1 & 0.3 & 0 & 0.0 & 0.671 \\
\hline & While & 301 & 96.5 & 52 & 96.3 & 0.207 \\
\hline & Unknown & 1 & 0.3 & 1 & 1.9 & \\
\hline \multirow[t]{6}{*}{ Tumor site } & Distant metastasis & 6 & 1.9 & 0 & 0.0 & 0.295 \\
\hline & Extremities & 134 & 42.9 & 20 & 37.0 & 0.312 \\
\hline & Head and neck & 22 & 7.1 & 6 & 11.1 & 0.341 \\
\hline & Regional cutaneous ${ }^{\mathrm{a}}$ & 3 & 1.0 & 4 & 7.4 & 0.002 \\
\hline & Trunk & 118 & 37.8 & 18 & 33.3 & 0.418 \\
\hline & Unknown & 11 & 3.5 & 1 & 1.9 & $N / A$ \\
\hline \multirow[t]{3}{*}{ Current tumor status } & Tumor free & 138 & 44.2 & 33 & 61.1 & 0.042 \\
\hline & With tumor & 157 & 50.3 & 18 & 33.3 & 0.012 \\
\hline & Unknown & 17 & 5.4 & 3 & 5.6 & $\mathrm{~N} / \mathrm{A}$ \\
\hline \multirow[t]{6}{*}{ Clark level at diagnosis } & I & 5 & 1.6 & 0 & 0.0 & 0.340 \\
\hline & II & 13 & 4.2 & 2 & 3.7 & 0.836 \\
\hline & III & 51 & 16.3 & 9 & 16.7 & 0.959 \\
\hline & IV & 113 & 36.2 & 18 & 33.3 & 0.558 \\
\hline & V & 40 & 12.8 & 3 & 5.6 & 0.109 \\
\hline & Unknown & 90 & 28.8 & 22 & 40.7 & $\mathrm{~N} / \mathrm{A}$ \\
\hline \multirow{2}{*}{ Primary melanoma ulceration } & Yes & 123 & 39.4 & 17 & 31.5 & 0.198 \\
\hline & Unknown & 85 & 27.2 & 21 & 38.9 & $\mathrm{~N} / \mathrm{A}$ \\
\hline \multirow[t]{7}{*}{$\mathrm{T}$} & T0 & 15 & 4.8 & 7 & 13.0 & 0.025 \\
\hline & Tis & 7 & 2.2 & 0 & 0.0 & 0.258 \\
\hline & $\mathrm{T} 1$ & 24 & 7.7 & 5 & 9.3 & 0.752 \\
\hline & $\mathrm{T} 2$ & 57 & 18.3 & 9 & 16.7 & 0.693 \\
\hline & T3 & 63 & 20.2 & 6 & 11.1 & 0.094 \\
\hline & $\mathrm{T} 4$ & 102 & 32.7 & 15 & 27.8 & 0.382 \\
\hline & TX & 44 & 14.1 & 12 & 22.2 & $\mathrm{~N} / \mathrm{A}$ \\
\hline \multirow[t]{5}{*}{$\mathrm{N}$} & No & 149 & 47.8 & 31 & 57.4 & 0.295 \\
\hline & N1 & 54 & 17.3 & 7 & 13.0 & 0.373 \\
\hline & $\mathrm{N} 2$ & 36 & 11.5 & 7 & 13.0 & 0.837 \\
\hline & N3 & 41 & 13.1 & 4 & 7.4 & 0.207 \\
\hline & $N X$ & 32 & 10.3 & 5 & 9.3 & $\mathrm{~N} / \mathrm{A}$ \\
\hline \multirow[t]{3}{*}{$M$} & M0 & 275 & 88.1 & 51 & 94.4 & 0.806 \\
\hline & $\mathrm{M}^{\mathrm{b}}$ & 21 & 6.7 & 0 & 0.0 & 0.046 \\
\hline & $\mathrm{MX}$ & 16 & 5.1 & 3 & 5.6 & $\mathrm{~N} / \mathrm{A}$ \\
\hline \multirow[t]{5}{*}{ Stage } & Stage 0 & 6 & 1.9 & 0 & 0.0 & 0.295 \\
\hline & Stage I & 50 & 16.0 & 10 & 18.5 & 0.733 \\
\hline & Stage II & 80 & 25.6 & 16 & 29.6 & 0.646 \\
\hline & I/II/not sure & 6 & 1.9 & 4 & 7.4 & 0.027 \\
\hline & Stage III & 125 & 40.1 & 18 & 33.3 & 0.263 \\
\hline
\end{tabular}


Table 1 (Continued)

\begin{tabular}{|c|c|c|c|c|c|c|}
\hline \multirow[t]{2}{*}{ Variable } & \multirow[t]{2}{*}{ Categories } & \multicolumn{2}{|c|}{ FVIII nonmutated $(n=312)$} & \multicolumn{2}{|c|}{ FVIII mutated $(n=54)$} & \multirow[t]{2}{*}{$p$-Value } \\
\hline & & Number of cases & $\%$ & Number of cases & $\%$ & \\
\hline \multirow[t]{3}{*}{ Postoperative chemotherapy } & No & 210 & 67.3 & 44 & 81.5 & 0.093 \\
\hline & Yes & 62 & 19.9 & 6 & 11.1 & 0.104 \\
\hline & Unknown & 40 & 12.8 & 4 & 7.4 & $N / A$ \\
\hline \multirow[t]{3}{*}{ Postoperative radiation } & No & 287 & 92.0 & 50 & 92.6 & 0.503 \\
\hline & Yes & 16 & 5.1 & 4 & 7.4 & 0.540 \\
\hline & Unknown & 9 & 2.9 & 0 & 0.0 & $N / A$ \\
\hline
\end{tabular}

Abbreviations: $\mathrm{M}$, distant metastases; N, lymph node; N/A, not determined; $\mathrm{T}$, tumor; $\mathrm{X}$ after T, N, M indicates unknown status.

Values in bold indicate the difference between the two groups is statistically significant with $p<0.05$.

${ }^{\text {a } T h i s ~ c a t e g o r y ~ i n c l u d e s ~ s a t e l l i t e ~ a n d ~ i n-t r a n s i t ~ m e t a s t a s i s . ~}$

${ }^{b}$ All 21 metastatic cases were found in the FVIII nonmutated group.

VWF, and ADAMTS13 were also reported in diffuse large B cell lymphoma (22.9\%), small cell lung carcinoma (20.7\%), cholangiocarcinoma (20.0\%), and colorectal adenocarcinoma (19.4\%; - Fig. 1).

\section{Characteristics of Patients with or without FVIII Mutations}

In the provisional "TCGA skin cutaneous melanoma" dataset, 54 patients had FVIII mutations and 312 patients had no FVIII mutation. All mutations found by WES were confirmed by RNAseq in the same specimen, which were not present in the genomic DNA isolated from the patient leukocytes. ${ }^{17,19}$ No

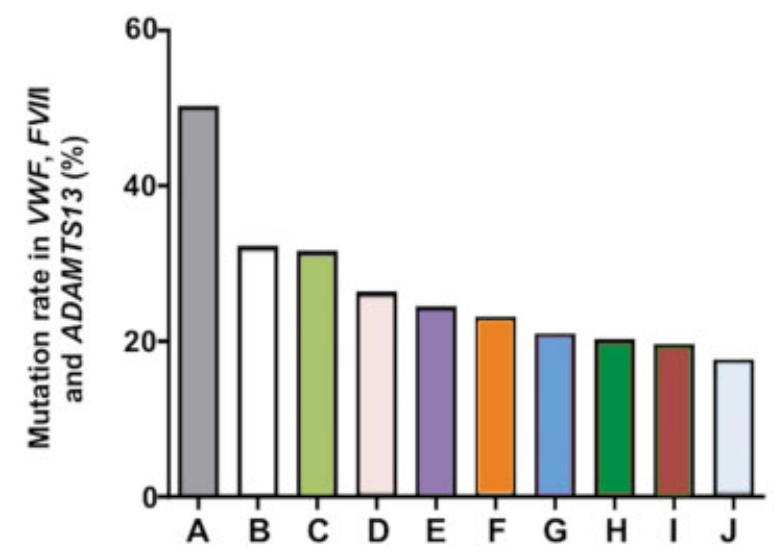
A. Desmoplastic melanoma (Nat. Genet. 2015)
B. Melanoma (Nat. 2012)
C. Skin cutaneous melanoma (Cell 2012)
D. Skin cutaneous melanoma (TCGA, Provisional)
E. Skin cutaneious melanoma (Nat. Genet. 2012)
F. Large B cell lymphoma (TCGA, Provisional)
G. Small cell lung cancer (Nat. Genet. 2012)
H. Colangiocarcinoma (Nat. Genet. 2013)
I. Colorectal adenocarcinoma (Nat. 2012)
J. Lung squamous cell carcinoma (Nat. 2012)

Fig. 1 Top-10 cancer studies show the highest mutation rates in genes encoding FVIII, VWF, and ADAMTS13. The rates of FVIII, VWF, and ADAMTS13 mutations were obtained by searching database among 126 cancer studies using cBioPortal. Each bar represents the percentage of mutation found in all three genes (e.g., FVIII, VWF, and ADAMTS13) in each individual study. significant difference was identified between patient's age, gender, Clark's level, Breslow's thickness, primary tumor ulceration, lymph node status, stage, overall copy number variation, and the percentage of postoperative chemo/radiation therapy in melanoma patients with and without FVIII mutations except for mutations counts (- Table 1 and - Supplementary Table $\mathbf{1}$ ). However, Fisher's exact test demonstrated that all 21 cases (6.7\%) with metastasis were all reported in the FVIII nonmutated group, but no metastatic case $(0 \%)$ was reported in the FVIIImutated group $(p=0.046)$. Furthermore, patients with the FVIII mutation are more likely to be in the tumor-free group (61.1 vs. $44.2 \%, p=0.042 ;$ - Table 1). Interestingly, the overall mutation counts were also significantly higher in the FVIIImutated group than in the FVIII nonmutated group $(p=0.013 ;$ - Supplementary Table 1$)$.

\section{Mutation Profiles in FVIII, VWF, and ADAMTS13 in Cutaneous Melanoma}

Among five melanoma studies, the provisional "TCGA skin cutaneous melanoma" project was the largest one with sequencing data from 479 samples. This was also the only cohort with corresponding pathological and clinical information described earlier for each patient. The mutation rates in FVIII, $V W F$, and ADAMTS13 from the TCGA provisional datasets were 15,14 , and $5 \%$, respectively (-Fig. 2A). Similar results were obtained from other two datasets: 121 Broad patients (-Fig. 2B) ${ }^{17}$ and 91 Yale patients ${ }^{18}$ (-Fig. 2C). A majority of mutations identified were missense and nonsense resulting in amino acid changes and a truncation of FVIII protein, respectively. The number of mutations in FVIII, VWF, and ADAMTS13 appeared to directly correlate with the length of coding regions of the genes $\left(r^{2}=0.993\right)$. However, there was no evidence of a mutational hotspot in any of these three genes (FVIII, VWF, and ADAMTS13; - Fig. 3). All these gene mutations found by WES were verified with the RNA-Seq analysis in the same tumor samples, which were not present in the genomic DNA isolated from leukocytes of the patients. ${ }^{17-19}$ These results suggest the somatic mutation, rather than inherited. These mutated gene products were expressed in the tumor cells. Furthermore, there was a strong tendency of coexistence of mutations in both FVIII and VWF or in both VWF and ADAMTS13 in a single patient (not shown). 


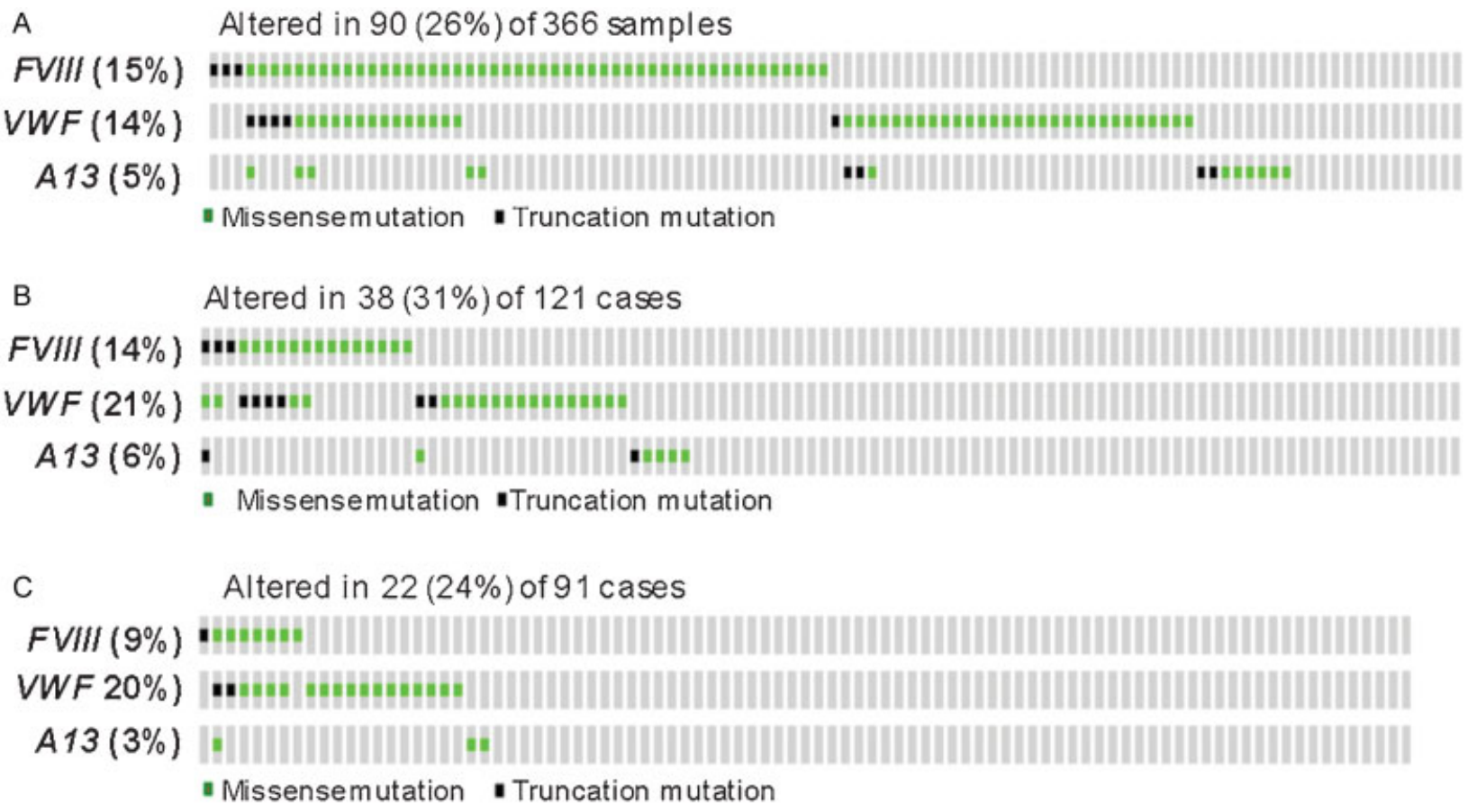

Fig. 2 Mutation profiles of FVIII, VWF, and ADAMTS13 found in cutaneous melanoma of three datasets. (A) TCGA provisional; (B) broad cell, 2012; and (C) Yale Nature Genetics, 2012.
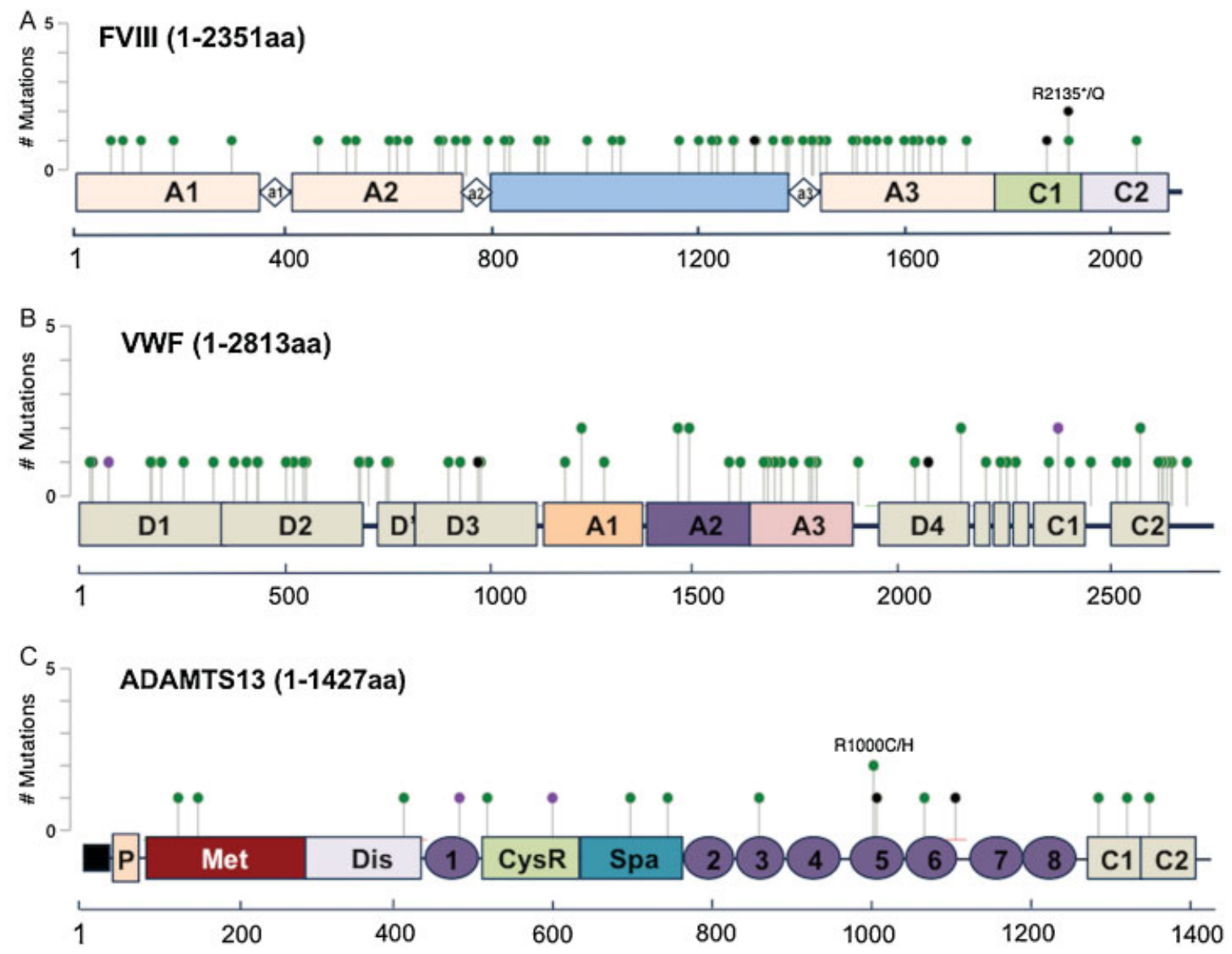

Fig. 3 Detailed mutation maps of FVIII, VWF, and ADAMTS13 found in patients with cutaneous melanoma. Each dot above the protein molecule represents a mutation, which spreads across the entire encoded protein of FVIII (A), VWF (B), and ADAMTS13 (C). There is no evidence of a "hotspot" of gene mutations. 


\section{Effect of Somatic Mutations in FVIII, VWF, and ADAMTS13 on the Overall Survival of Melanoma Patients}

Log-rank test showed that mutations in FVIII ( - Fig. 4A), but not in VWF (-Fig. 4B) and ADAMTS13 (-Fig. 4C), were significantly associated with a better survival rate in melanoma patients. In addition, no association was found between the combined mutations of VWF, FVIII, and ADAMTS13 with the long-term survival rate (-Fig. 4D). Interestingly, low VWF, but not FVIII and ADAMTS13, mRNA expression in the melanoma tissue itself was associated with a better overall survival rate $(p=0.02 ;$ - Fig. $4 \mathrm{E})$, suggesting that the decreased VWF gene expression in association with FVIII mutations may have a protective effect in patients with melanoma. Specifically, patients with the FVIII mutations had a median survival of 269 months compared with the median survival of 67 months in those without the FVIII mutations $(p=0.02)$.

\section{The Effect of Mutations on mRNA and Protein Expressions of FVIII, VWF, and ADAMTS13 in Melanoma Patients}

To investigate the possible underlying mechanism of the protective role of FVIII mutations in patients with cutaneous melanoma, we tested the effect of mutations in FVIII, VWF, and ADAMTS13 on mRNA expression based on the RNA-Seq data. As shown, FVIII mutations did not result in a significant alteration of VWF ( - Fig. 5A) and ADAMTS13 mRNA expression ( $\mathbf{- F i g . ~ 5 B ) , ~ b u t ~ t h e y ~ d i d ~ s i g n i f i c a n t l y ~ l o w e r ~ t h e ~ F V I I I ~}$ mRNA expression $(p<0.001)$ as one might anticipate ( $\mathbf{- F i g}$. 5C). We further tested the entire mRNA expression profile in the tumor tissue from patients with FVIII mutations. Using both $p$-value (Student's t-test) and Q-value (false discovery rate) less than 0.05 as the inclusion criteria, we identified a total of 44 genes with a significant difference between those with the FVIII mutations and those without (-Supplementary Table 2). A total of 38 genes showed an
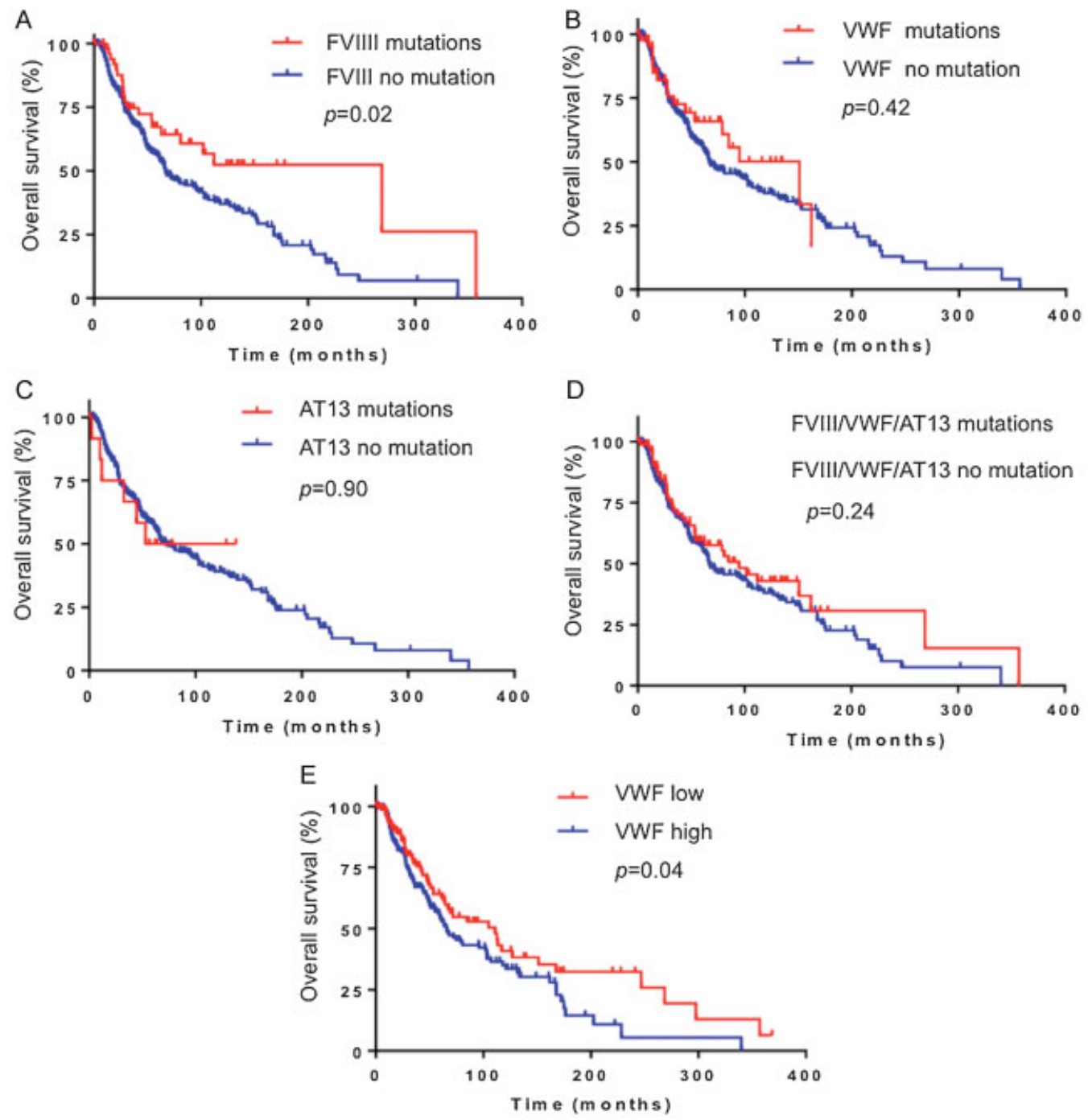

Fig. 4 Association of mutations in FVIII, VWF, and ADAMTS13 and their expression levels with the long-term outcomes of cutaneous melanoma. (A) FVIII mutations are associated with a better overall survival rate $(p=0.02)$. (B and C) VWF and ADAMTS13 (AT13) mutations are not associated with a better overall survival rate ( $p=0.42$ and $p=0.90$, respectively). (D) Combined mutations of VWF/FVIII/AT13 are not associated with an overall survival rate $(p=0.24)$. (E) Low VWF mRNA expression is associated with a better survival rate $(p=0.04)$. 

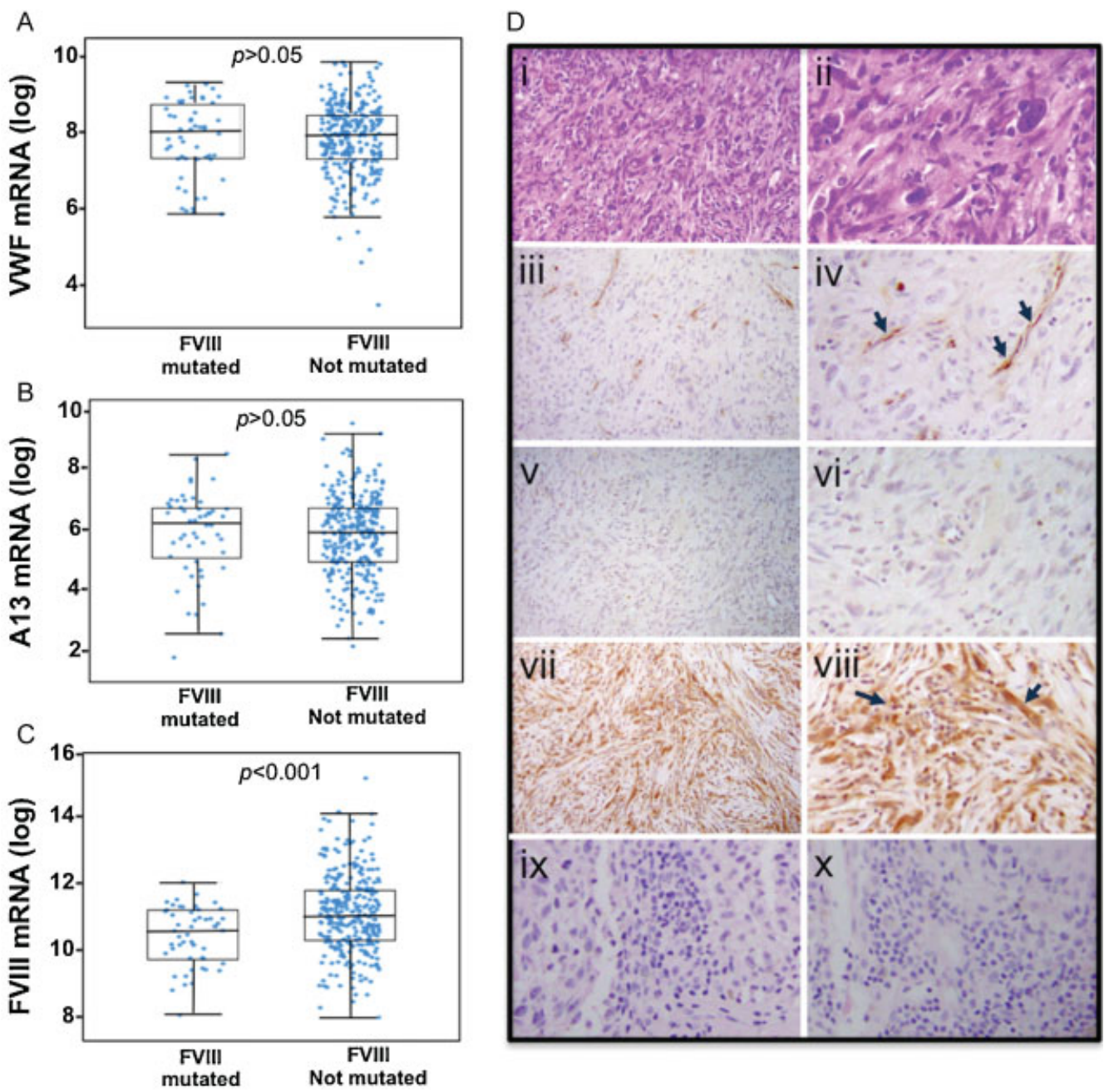

Fig. 5 Association between mutations in FVIII and expression of VWF, FVIII, and ADAMTS13 mRNA in patients with cutaneous melanoma. The levels of mRNA expression (mean $\pm 95 \%$ confidential interval) for VWF (A), FVIII (B), and ADAMTS13 (C) in patients with or without $F V I I I$ mutations. (D). Hematoxylin and eosin staining (i and ii) and immunohistochemistry with rabbit anti-VWF IgG (iii and iv), sheep anti-FVIII IgG (v and vi), and rabbit anti-ADAMTS13 IgG (vii and viii), followed by streptavidin-peroxidase conjugated anti-rabbit IgG or anti-sheep IgG or secondary antibody only (ix and x).

increased expression of mRNA in the FVIII-mutated group and 6 genes, including $V W F$, showed decreased mRNA expression in FVIII-mutated group compared with FVIII nonmutated group (- Supplementary Table 2).

VWF is produced in all vascular endothelium; FVIII is expressed only in the sinusoidal and pulmonary vascular endothelium; ADAMTS13 is primarily synthesized in hepatic stellate cells, ${ }^{20}$ but also found in trace amount in the vascular endothelium $^{21,22}$ and platelets. $^{23}$ While VWF, FVIII, and ADAMTS13 mRNAs were identified in the melanoma tissues through RNA-Seq analysis, the protein expression has never been examined in tumor tissues. We set to determine the protein expression in seven melanoma cases by immunohistochemistry. The results showed that VWF ( - Fig. 5D, iii and iv) and FVIII ( $\mathbf{- F i g . 5 D , v}$ and vi) were not detected in the melanoma cells, but ADAMTS13 immune reactivity was strongly positive in melanoma cells ( - Fig. 5D, vii and viii). Control staining was negative when primary antibodies were omitted ( - Fig. 5D, ix and $\mathrm{x}$ ). The specific VWF staining was detected in the vascular endothelium within the melanoma tissues ( - Fig. 5D, iii and iv, arrowheads). These results demonstrate that while mRNAs for VWF, FVIII, and ADAMTS13 are all expressed in melanoma tissue, the protein concentrations of VWF and FVIII, but not ADAMTS13, in the tumor tissues may be quite low.

\section{Discussion}

This study highlights the high mutation rates in genes encoding FVIII, VWF, and ADAMTS13 in patients with metastatic cutaneous melanoma (-Figs. 1-3). The presence of mutations in FVIII, but not in VWF and ADAMTS13 or a combined mutation rate of FVIII, VWF, and ADAMTS13, is associated with a more favorable overall survival in these patients (-Fig. 4). The results suggest that the mutation burden in FVIII may be useful as a prognostic marker. These results may also suggest a potential role of FVIII protein and its carrier protein VWF in the pathobiology of melanoma including tumor growth and metastasis by affecting the tumor microenvironment. 
Table 2 Expression of VWF, FVIII, and ADAMTS13 in melanoma tissues by immunohistochemistry

\begin{tabular}{|c|c|c|c|c|c|c|c|c|c|}
\hline \multirow{2}{*}{$\begin{array}{l}\text { Case } \\
\text { no. }\end{array}$} & \multirow{2}{*}{$\begin{array}{l}\text { Age at } \\
\text { diagnosis } \\
\text { (y) }\end{array}$} & \multirow[t]{2}{*}{ Gender } & \multirow[t]{2}{*}{ Diagnosis } & \multirow[t]{2}{*}{ Location } & \multirow{2}{*}{$\begin{array}{l}\text { Clark } \\
\text { level }\end{array}$} & \multirow{2}{*}{$\begin{array}{l}\text { Breslow } \\
\text { depth }\end{array}$} & \multicolumn{3}{|c|}{ Melanoma } \\
\hline & & & & & & & FVIII & VWF & ADAMTS13 \\
\hline 1 & 85 & Male & Recurrent melanoma & Face & $\mathrm{N} / \mathrm{A}$ & $\mathrm{N} / \mathrm{A}$ & $(-)$ & $(-)$ & $(+++)$ \\
\hline 2 & 63 & Female & Melanoma & Right arm & $\mathrm{N} / \mathrm{A}$ & $\mathrm{N} / \mathrm{A}$ & $(-)$ & $(-)$ & $(-)$ \\
\hline 3 & 69 & Female & Invasive melanoma & Left thigh & III & $0.8 \mathrm{~mm}$ & $(-)$ & $(-)$ & $(++)$ \\
\hline 4 & 35 & Female & Invasive melanoma & Left abdomen & II & $0.38 \mathrm{~mm}$ & $(-)$ & $(-)$ & $(+)$ \\
\hline 5 & 64 & Female & Melanoma & Right parietal scalp & $\mathrm{V}$ & $4.15 \mathrm{~mm}$ & $(-)$ & $(-)$ & $(++)$ \\
\hline 6 & 84 & Male & Invasive melanoma & Left cheek & III & $0.45 \mathrm{~mm}$ & $(-)$ & $(-)$ & $(++)$ \\
\hline 7 & 67 & Male & Invasive melanoma & Right lateral chest & & $0.65 \mathrm{~mm}$ & $(-)$ & $(-)$ & $(++)$ \\
\hline
\end{tabular}

Abbreviations: ADATMS13, a disintegrin and metalloprotease with thrombospondin type 1 repeats 13; FVIII, factor VIII; N/A, not available; VWF, von Willebrand factor.

Note:,,-+++ , and +++ denote negative, mild, moderate, and strong positive in staining on tumor cells. VWF antibody stained all vessels.

As shown in our data, patients with the FVIII mutations exhibited significantly lower expression of the FVIII mRNA, which may be translated with the reduced levels of FVIII procoagulant activity in situ around the tumors (-Fig. 5), although immunohistochemical studies did not detect the FVIII protein in all seven cases of melanoma (-Fig. 5 and -Table 2). This may be caused by the low abundance of FVIII protein in any given cell. Further determination of FVIII synthesis and secretion from cultured melanoma cells with or without FVIII mutations may help better understand the pathophysiological relevance of the FVIII mutations.

The role of FVIII in melanoma biology has been previously investigated in animal studies. Hemophilia A mice lacking plasma FVIII activity were protective against the formation of lung metastatic foci after an intravenous inoculation of a murine melanoma cell line (B16F10). ${ }^{24,25}$ A single-dose infusion of human FVIII (100 U/kg) into hemophilia A mice significantly enhanced the lung metastasis of murine melanoma cells. ${ }^{25}$ In contrast, administration of a factor Xa inhibitor (i.e., tinzaparin) to wild-type mice ${ }^{26}$ or a direct thrombin inhibitor (i.e., lepirudin or argatroban) into wild-type mice ${ }^{27}$ and hemophilia $\mathrm{A}$ mice ${ }^{24,25}$ significantly reduced lung metastasis, suggesting that thrombin generation in the presence or absence of FVIII contributes to pulmonary metastasis. Thrombin is known to support tumor spreading and metastasis, predominantly mediated by the cleavage of a protease-activated receptor- 1 (PAR-1), which is highly expressed on the surface of platelets, endothelial cells, and metastatic cancer cells. ${ }^{28,29}$

The role of VWF and its cleaving protease ADAMTS13 in melanoma metastasis is much less clear. While mutation rates in VWF are not associated with the long-term outcome in patients with melanoma, its plasma levels or the presence of ultra-large VWF on endothelial surface is shown to be important for the development of thrombosis and tumor metastasis. $^{12,13,30,31}$ VWF is highly expressed in the vascular endothelium within the tumor, but not in the malignant melanoma cells themselves (-Fig. 5 and -Table 2). Therefore, VWF may be an important adhesion protein involving in thromboembolism and tumor metastatic process. Consistent with this notion, patients with melanoma had approximately twofold increase in their mean plasma concentrations of VWF antigen compared with the healthy controls $(24 \mathrm{vs} .14 \mu \mathrm{g} / \mathrm{mL}) .^{13}$ The increased levels of plasma VWF correlated with enhanced tumor progression in these patients. ${ }^{32}$ Blocking antibodies against VWF appeared to attenuate the binding of tumor cells to platelets by 75 to $81 \%{ }^{30}$ Paradoxically, lung colonization by cancer cells was enhanced in the VWF-knockout mice ${ }^{12}$ and inhibition of platelet glycoprotein Ib $\alpha$ led to significant increase in the formation of pulmonary foci of tumor cells. ${ }^{33}$ While the mutation burden in ADAMTS13 is not associated with the longterm outcome in patients with melanoma, reduced ADAMTS13 activity was reported in the tumor microenvironment or vessels, ${ }^{13}$ likely resulting from the locally released inflammatory cytokines (TNF- $\alpha$, IFN- $\gamma$, and IL-6), which may inhibit ADAMTS13 synthesis ${ }^{21}$ and activity. ${ }^{34}$ In seven cases we studied by immunohistochemistry, ADAMTS13 expression varied significantly from negative to strong positive (-Fig. 5 and - Table 2), although proteolytic activity of tissue-derived ADAMTS13 was not determined. Reduced ADAMTS13 activity may result in an accumulation of ultra-large VWF on endothelial surface and heightened platelet adhesion and aggregation, promoting thromboembolism and metastasis.

We conclude that high mutation rates in FVIII, but not in VWF and ADAMTS13, may have a value in predicting a longterm outcome in patients with cutaneous metastatic melanoma. The findings demonstrate a potential role of procoagulant factors in pathobiology of metastatic melanoma, providing a rationale for a novel therapeutic strategy in patients with metastatic melanoma.

\section{Authorship Contribution}

All the authors designed research, analyzed results, and wrote the article.

\section{Conflict of Interest}

X.L.Z. is a speaker for Alexion, a consultant for Ablynx and BioMedica, and received research support from Alexion. H.P.P. and L.A.W. participated in Phase 3 clinical trial for Ablynx. All other authors declared no conflict of interest associated with this study. 
Acknowledgments

This study was supported in part by R01s (HL126724 and HL115187) to X.L.Z. and ADAMS grant to P.Z.

\section{References}

1 Rickles FR, Levine M, Edwards RL. Hemostatic alterations in cancer patients. Cancer Metastasis Rev 1992;11(3-4):237-248

2 Bick RL. Coagulation abnormalities in malignancy: a review. Semin Thromb Hemost 1992;18(04):353-372

3 Svendsen E, Karwinski B. Prevalence of pulmonary embolism at necropsy in patients with cancer.J Clin Pathol 1989;42(08):805-809

4 Bastounis EA, Karayiannakis AJ, Makri GG, Alexiou D, Papalambros EL. The incidence of occult cancer in patients with deep venous thrombosis: a prospective study. J Intern Med 1996;239 (02):153-156

5 Amerio P, Manzoli L, Auriemma M, et al. Epidemiology and clinical and pathologic characteristics of cutaneous malignant melanoma in Abruzzo (Italy). Int J Dermatol 2009;48(07):718-722

6 Leslie MC, Bar-Eli M. Regulation of gene expression in melanoma: new approaches for treatment. J Cell Biochem 2005;94(01):25-38

7 Kong Y, Kumar SM, Xu X. Molecular pathogenesis of sporadic melanoma and melanoma-initiating cells. Arch Pathol Lab Med 2010;134(12):1740-1749

8 Kakkar AK. Antithrombotic therapy and survival in cancer patients. Best Pract Res Clin Haematol 2009;22(01):147-151

9 Young A, Chapman O, Connor C, Poole C, Rose P, Kakkar AK. Thrombosis and cancer. Nat Rev Clin Oncol 2012;9(08):437-449

10 Kerk N, Strozyk EA, Pöppelmann B, Schneider SW. The mechanism of melanoma-associated thrombin activity and von Willebrand factor release from endothelial cells. J Invest Dermatol 2010;130 (09):2259-2268

11 Terraube V, Marx I, Denis CV. Role of von Willebrand factor in tumor metastasis. Thromb Res 2007;120(Suppl 2):S64-S70

12 Terraube V, Pendu R, Baruch D, et al. Increased metastatic potential of tumor cells in von Willebrand factor-deficient mice. J Thromb Haemost 2006;4(03):519-526

13 Bauer AT, Suckau J, Frank K, et al. von Willebrand factor fibers promote cancer-associated platelet aggregation in malignant melanoma of mice and humans. Blood 2015;125(20):3153-3163

14 Vormittag R, Simanek R, Ay C, et al. High factor VIII levels independently predict venous thromboembolism in cancer patients: the cancer and thrombosis study. Arterioscler Thromb Vasc Biol 2009;29(12):2176-2181

15 Auwerda JJ, Sonneveld P, de Maat MP, Leebeek FW. Prothrombotic coagulation abnormalities in patients with newly diagnosed multiple myeloma. Haematologica 2007;92(02):279-280

16 Minnema MC, Fijnheer R, De Groot PG, Lokhorst HM. Extremely high levels of von Willebrand factor antigen and of procoagulant factor VIII found in multiple myeloma patients are associated with activity status but not with thalidomide treatment. J Thromb Haemost 2003;1(03):445-449

17 Hodis E, Watson IR, Kryukov GV, et al. A landscape of driver mutations in melanoma. Cell 2012;150(02):251-263
18 Krauthammer M, Kong Y, Ha BH, et al. Exome sequencing identifies recurrent somatic RAC1 mutations in melanoma. Nat Genet 2012;44(09):1006-1014

19 Shain AH, Garrido M, Botton T, et al. Exome sequencing of desmoplastic melanoma identifies recurrent NFKBIE promoter mutations and diverse activating mutations in the MAPK pathway. Nat Genet 2015;47(10):1194-1199

20 Uemura $M$, Tatsumi $K$, Matsumoto $M$, et al. Localization of ADAMTS13 to the stellate cells of human liver. Blood 2005;106 (03):922-924

21 Cao WJ, Niiya M, Zheng XW, Shang DZ, Zheng XL. Inflammatory cytokines inhibit ADAMTS13 synthesis in hepatic stellate cells and endothelial cells. J Thromb Haemost 2008;6(07):1233-1235

22 Turner N, Nolasco L, Tao Z, Dong JF, Moake J. Human endothelial cells synthesize and release ADAMTS-13. J Thromb Haemost 2006;4(06):1396-1404

23 Liu L, Choi H, Bernardo A, et al. Platelet-derived VWF-cleaving metalloprotease ADAMTS-13. J Thromb Haemost 2005;3(11): 2536-2544

24 Brüggemann LW, Versteeg HH, Niers TM, Reitsma PH, Spek CA. Experimental melanoma metastasis in lungs of mice with congenital coagulation disorders. J Cell Mol Med 2008;12(6B):2622-2627

25 Langer F, Amirkhosravi A, Ingersoll SB, et al. Experimental metastasis and primary tumor growth in mice with hemophilia A. J Thromb Haemost 2006;4(05):1056-1062

26 Amirkhosravi A, Mousa SA, Amaya M, Francis JL. Antimetastatic effect of tinzaparin, a low-molecular-weight heparin. J Thromb Haemost 2003;1(09):1972-1976

27 Asanuma K, Wakabayashi H, Hayashi T, et al. Thrombin inhibitor, argatroban, prevents tumor cell migration and bone metastasis. Oncology 2004;67(02):166-173

28 Nierodzik ML, Chen K, Takeshita K, et al. Protease-activated receptor 1 (PAR-1) is required and rate-limiting for thrombinenhanced experimental pulmonary metastasis. Blood 1998;92 (10):3694-3700

29 Belting M, Ahamed J, Ruf W. Signaling of the tissue factor coagulation pathway in angiogenesis and cancer. Arterioscler Thromb Vasc Biol 2005;25(08):1545-1550

30 Karpatkin S, Pearlstein E, Ambrogio C, Coller BS. Role of adhesive proteins in platelet tumor interaction in vitro and metastasis formation in vivo. J Clin Invest 1988;81(04):1012-1019

31 Nierodzik ML, Klepfish A, Karpatkin S. Role of platelets, thrombin, integrin IIb-IIIa, fibronectin and von Willebrand factor on tumor adhesion in vitro and metastasis in vivo. Thromb Haemost 1995; 74(01):282-290

32 Damin DC, Rosito MA, Gus P, Roisemberg I, Bandinelli E, Schwartsmann G. Von Willebrand factor in colorectal cancer. Int J Colorectal Dis 2002;17(01):42-45

33 Erpenbeck L, Nieswandt B, Schön M, Pozgajova M, Schön MP. Inhibition of platelet GPIb alpha and promotion of melanoma metastasis. J Invest Dermatol 2010;130(02):576-586

34 Bernardo A, Ball C, Nolasco L, Moake JF, Dong JF. Effects of inflammatory cytokines on the release and cleavage of the endothelial cell-derived ultralarge von Willebrand factor multimers under flow. Blood 2004;104(01):100-106 